\title{
PARQUE VIVA A CIÊNCIA: UM NOVO ESPAÇO DE DIVULGAÇÃO CIENTÍFICA EM FLORIANÓPOLIS
}

Originais recebidos em: 15/02/2011

Aceito para publicação em: 19/09/2011

Aline Batista

alinebtt@gmail.com

Universidade Federal de Santa Catarina

Débora Peres Menezes debora@ffsc.ufsc.br

Universidade Federal de Santa Catarina

Nelson Canzian Silva canzian@fsc.ufsc.br

Universidade Federal de Santa Catarina

Vilmar Minella Junior vilmar_jr@grad.ufsc.br Universidade Federal de Santa Catarina

\section{Resumo}

O Parque Viva a Ciência é um espaço que visa mitigar o grande déficit de centros de ciências na mesorregião de Florianópolis. Neste artigo compara-se o número de alunos matriculados em escolas da região com o número de centros de ciências, apontando a dificuldade daqueles em visitar tais espaços de divulgação científica durante o seu ciclo básico de estudo. Descrevem-se os 10 brinquedos de grande porte que se encontram ao ar livre nas instalações do Parque Viva a Ciência desde 2008 e comentam-se as estratégias de mediação empregadas para promover e problematizar a interação entre os visitantes e os equipamentos. Apresentam- se dados sobre o número e o perfil do público escolar visitante, constatando-se que há uma grande demanda por esse tipo de espaço.

Palavras-chave: Divulgação científica. Centros de ciências. Brinquedos científicos.

\section{PARQUE VIVA A CIENNCIA: A NEW SCIENTIFIC EXHIBITION CENTER IN FLORIANÓPOLIS}

\begin{abstract}
The Parque Viva a Ciência (Save the Science Center) is a place that aims to reduce the large deficit of science centers in the Florianópolis region. In this article we compare the number of students registered in schools in the region with the number of science centers, pointing out the difficulty in visiting these scientific places during their basic cycle of studies. We also describe 10 large outdoor equipments (toys) in operation since 2008 and comment on the mediation strategies used to promote and discuss the interaction between visitors and the equipments. We present data on the number and profile of public school visitors and conclude that there is a great demand for this type of space.
\end{abstract}

Keywords: Science centers. Scientific toys. Scientific equipments (toys). 


\section{INTRODUÇÃO}

Centros e museus de ciências são espaços de divulgação científica que oferecem aos visitantes oportunidades para refletir sobre os fenômenos observados e sentidos (MARANDINO, 2005). Eles têm sido considerados excelentes aliados do ensino formal (CHINELLI; PEREIRA; AGUIAR, 2008). Tais espaços empregam a sensibilização dos sentidos e a socialização entre os pares escolares, com o auxílio de equipamentos, exposições e oficinas, para aproximar os estudantes da ciência. No caso do Parque Viva a Ciência, o passeio é, em geral, guiado por mediadores, que questionam o senso comum do visitante e apresentam a visão da ciência estabelecida.

Atualmente existem no Estado de Santa Catarina oito espaços destinados a atender escolares com o intuito de divulgar a ciência e realizar atividades complementares à sala de aula (ABCMC, 2009). Os temas desses espaços contemplam fauna e flora, arqueologia e ciências naturais. Na Fundação Ecológica e Zoobotânica de Brusque, os visitantes podem apreciar 150 animais de 64 espécies diferentes e conhecer o orquidário e bromelário (FEZB, 2010); em uma visita ao Zoológico Pomerode, é possível encontrar 230 espécies de animais (ABCMC, 2009); a exposição de fósseis do Museu da Terra e da Vida em Mafra apresenta um acervo de 5.000 peças (ABCMC, 2009); e o Museu Oceanográfico Univali, em Piçarras, realiza atividades expositivas e de pesquisa com ênfase na fauna marinha brasileira (ABCMC, 2009).

Os outros quatro espaços listados estão em Florianópolis e todos são de pequeno porte. $\mathrm{O}$ Museu do Homem do Sambaqui é especializado em arqueologia pré-histórica com um acervo de 5.000 peças $(\mathrm{ABCMC}, 2009)$ e com capacidade para atender diariamente quatro grupos de 25 estudantes; o Parque Viva a Ciência, que conta com dez equipamentos interativos dispostos ao ar livre, utiliza visitas mediadas para uma aproximação dos visitantes com a física e atende cerca de quatro grupos com 35 estudantes por dia; o Planetário da Universidade Federal de Santa Catarina (UFSC), que possui uma cúpula com seis metros de diâmetro e um projetor digital, realiza quatro sessões diárias para 38 pessoas, as quais são reservadas a grupos escolares, há também um horário durante a semana que é aberto à comunidade; e a Sala de Ciência do SESC, que realiza demonstrações de equipamentos de bancada (ABCMC, 2009), possibilita a visitação de até 100 pessoas por dia. 
Convém ressaltar que, nos casos do Parque Viva a Ciência e do Planetário da UFSC, o número de escolas atendidas poderia ser maior (quase o dobro), não fossem as limitações impostas pelos horários escolares e as dificuldades de transporte de alunos.

Segundo o guia da $\mathrm{ABCMC}$, a região da grande Florianópolis concentra 50\% dos Centros e Museus de Ciências do estado. Possui 21 municípios com 967.159 habitantes (IBGE, 2010a) distribuídos em $7.349 \mathrm{~km}^{2}$ de área (IBGE, 2010b), conta com 884 escolas que atendem 162.840 alunos matriculados, desde a pré-escola até o ensino médio e a educação de jovens e adultos (INEP, 2010).

Com base no número de alunos existentes na educação básica e considerando a importância da presença desses espaços na vida escolar, não é difícil perceber que a grande Florianópolis possui um déficit de espaços de ciências voltados ao entendimento desses estudantes. Tais centros têm o potencial de receber um total aproximado de 88.400 alunos operando todos os 200 dias de um ano letivo. Assim sendo, constata-se que os 162.840 estudantes precisam aguardar em uma "fila de espera" de 1,9 anos para visitarem pelo menos um desses locais. Já para conhecer os quatro espaços, esse tempo passaria para 7,6 anos. Fica clara, portanto, a deficiência de espaços de ciências em Santa Catarina, uma vez que uma criança que ingressa hoje na pré-escola na grande Florianópolis poderá concluir o ciclo básico sem ter experimentado o que esses espaços oferecem.

Este estudo tem por objetivo apresentar o projeto e as ações realizadas no Parque Viva a Ciência. A seguir serão descritos os equipamentos disponíveis e os conceitos científicos envolvidos, o atendimento feito através de mediações e o perfil do público visitante.

\section{MATERIAL E MÉTODOS}

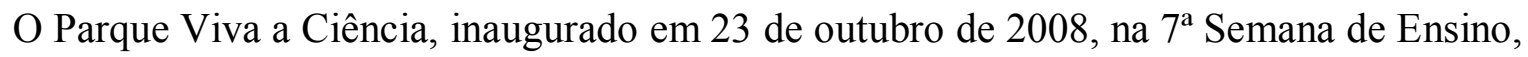
Pesquisa e Extensão (SEPEX) da UFSC, é um espaço localizado em torno do Planetário no campus de Florianópolis. Os brinquedos educativos estão instalados em uma área de cerca de $1.000 \mathrm{~m}^{2}$. Foi concebido como projeto-piloto de um grande parque a ser instalado em uma área de 50 mil $\mathrm{m}^{2}$ cedida à UFSC pela União para este fim.

O Parque atende a comunidade em geral e recebe grupos escolares. A partir de 2009 passou a realizar agendamento prévio, por marcação direta, com a secretaria do Planetário ou 
pelo programa "Venha Conhecer a UFSC" (VCU, 2010). O Parque Viva a Ciência conta com um grupo de aproximadamente 14 estudantes universitários que atuam como mediadores.

Por estar cercado de árvores e seus brinquedos serem coloridos, o Parque apresenta grande impacto visual, sendo possível explorar diversos conceitos físicos de uma maneira agradável ao visitante. Ao longo dos anos de existência, os mediadores têm realizado ações que contribuem para a formação da identidade do projeto. Foi criado um circuito que disponibiliza aos grupos escolares a participação em uma sessão no planetário, por cerca de uma hora, e o mesmo tempo para que eles possam interagir com os mediadores e seus pares em cada equipamento. Essas ações procuram alcançar uma nova perspectiva do ensino de ciências através da observação e, principalmente, da experimentação de uma forma ativa no processo de investigação. Elas permitem a verificação de hipóteses, e em muitos casos ocorrem mudanças de pré-concepções equivocadas ou até então nunca questionadas.

Os estudantes do curso de física, através da mediação, buscam levantar concepções prévias dos visitantes, problematizando seus comentários a respeito do que veem. Os mediadores têm papel essencial na apresentação dos brinquedos e na condução do raciocínio dos visitantes para um melhor aproveitamento do espaço e para uma melhor compreensão dos conceitos. O indutivismo é ferramenta presente nas mediações, valorizando as conexões que o estudante eventualmente faz a respeito dos fenômenos com situações do seu cotidiano.

$\mathrm{Na}$ maioria dos casos, a turma é acompanhada pelo seu professor de ciências. Inicialmente é feita uma breve apresentação do local, informando os visitantes que a experimentação em cada brinquedo acontece concomitantemente à análise e discussão da ciência básica associada ao equipamento. Em seguida, os mediadores conduzem os estudantes através de um circuito, passando de brinquedo em brinquedo. Em frente a cada um deles, o mediador, inicialmente, procura instigar os estudantes a pensarem sobre os aspectos da física relacionados ao seu funcionamento. Com a ajuda do mediador, os estudantes vão fazendo observações e análises do equipamento, tendo a oportunidade de construir hipóteses para a resolução das situaçõesproblema apresentadas e, após experimentar, refutá-las ou confirmá-las.

A expectativa é que o visitante passe a interagir com os brinquedos de maneira diferente e com maior curiosidade. Aproveitando esta situação, e considerando o interesse, a faixa etária e a escolaridade dos visitantes, o mediador apresenta os conceitos físicos relacionados ao equipamento em diferentes níveis de formalização. 
A relação seguinte apresenta os brinquedos, a sua caracterização, e os conceitos que os mediadores do parque abordam durante a mediação:

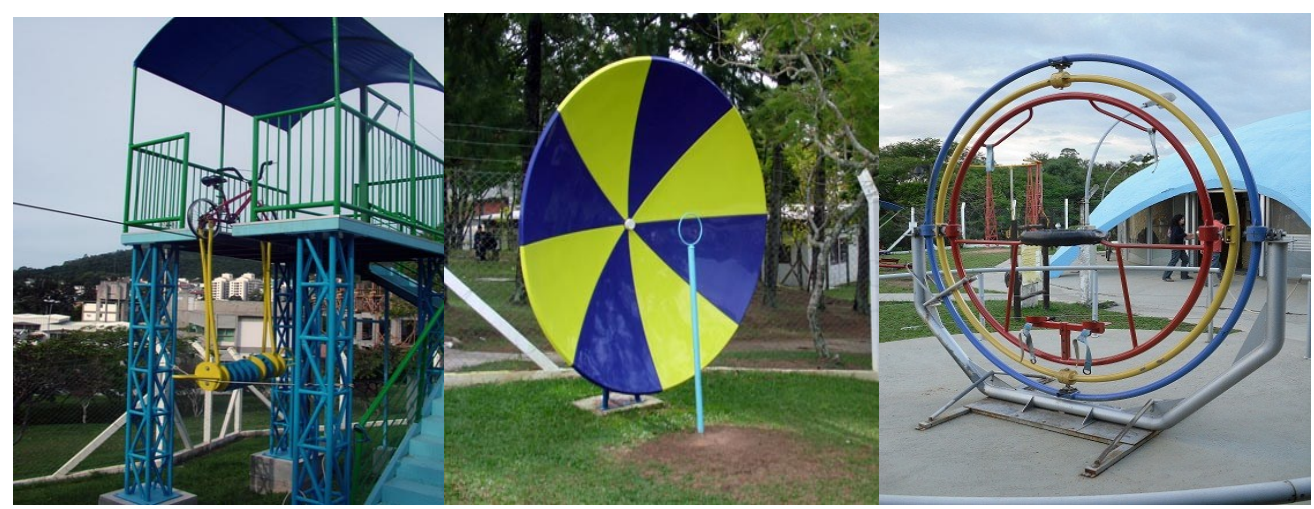

Figura 1 - Bicicleta suspensa, parabólica e gira-gira. Fonte: Os autores.

- Bicicleta suspensa: instrumento que anda sobre um cabo de aço. Aplicam-se a distribuição de massa, o equilíbrio e o ponto de apoio.

- Parabólica: duas parabólicas distantes, com o uso das quais é possível conversar. Explicam-se ondas, propagação do som e reflexão de ondas.

- Gira-gira: sistema de anéis com mancais ortogonais onde a pessoa pode girar livremente. Abordam-se o centro de massa, equilíbrio, graus de liberdade e energia potencial gravitacional.

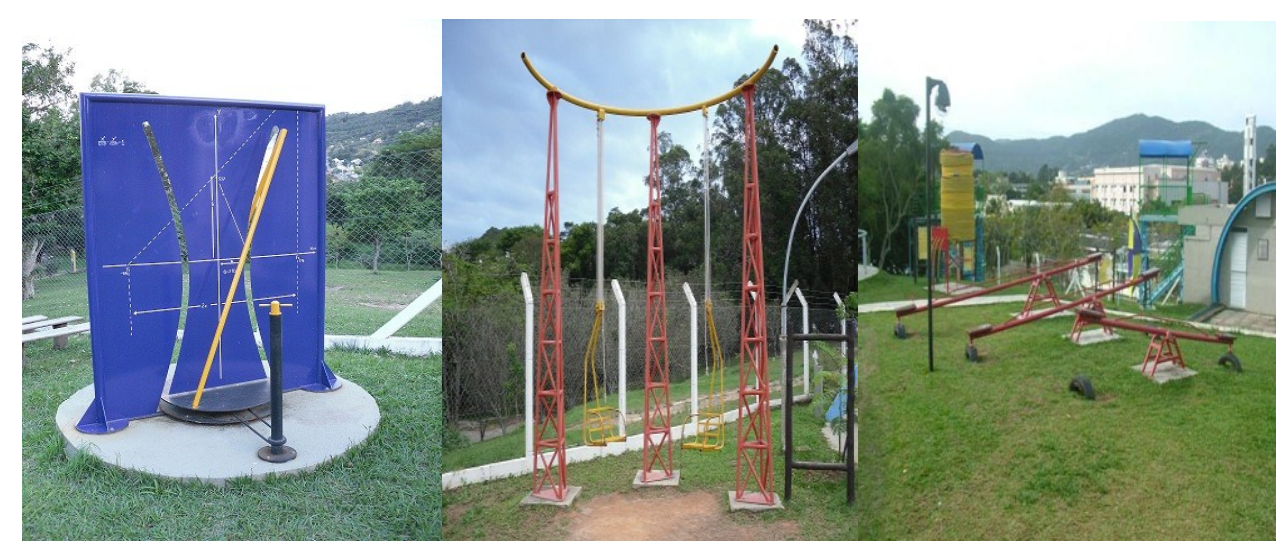

Figura 2 - Hipérbole, cadeiras autoelevatórias e gangorras.

Fonte: Os autores. 
- Hipérbole: duas retas unidas que passam através de duas fendas em um plano. São esclarecidos secções cônicas e sólidos de revolução.

- Cadeiras autoelevatórias: duas cadeiras que diferem no número de roldanas empregadas para elevá-las. Explicam-se sistema de roldanas, força, trabalho e energia mecânica.

- Gangorras: três gangorras com braços de tamanhos diferentes. Explicam-se alavancas, ponto de apoio, distribuição de massa, força e torque.

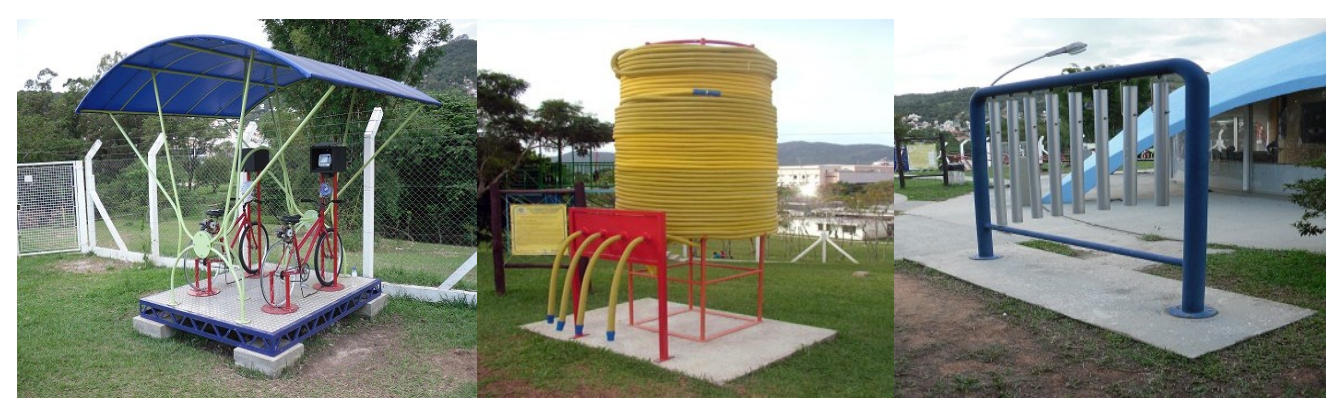

Figura 3 - Bicicletas, mangueiras e tubos sonoros.

Fonte: Os autores.

- Bicicletas: duas bicicletas com dínamos para produzir eletricidade e fazer funcionar $\mathrm{TV}$, rádio e ventiladores acoplados. Relatam-se transformações de energia, indução eletromagnética, potencial elétrico e corrente elétrica.

- Mangueiras: Duas mangueiras longas enroladas com tamanhos diferentes (150 m e $250 \mathrm{~m}$ ). Explicam-se velocidade média, velocidade do som, propagação do som e velocidade da luz.

- Tubos sonoros: tubos de metal com tamanhos diferentes. Explicam-se frequência, propagação do som, altura do som (grave e agudo) e notas musicais.

Neste sentido, entendemos que as mediações são fundamentais para promover o envolvimento e aprendizado do visitante. Existem diversos roteiros pré-estabelecidos para os diferentes brinquedos e perfis de público, com flexibilidade para serem adequados a novos caminhos sugeridos pelos interesses dos visitantes. Por exemplo, para os balanços com diferentes comprimentos, a abordagem mais simples discute apenas conceitos básicos, tais como: o que são oscilações, período e frequência. Já para turmas mais avançadas, é possível comparar a diferença entre os períodos de oscilação quando o visitante está em pé ou sentado, alterando a posição do centro de massa, sempre sem o uso de equações ou vocabulário específico que o visitante desconheça. 


\section{RESULTADOS E ANÁLISE}

Nos dois meses de funcionamento do ano de sua inauguração, foram atendidos 2.271 visitantes. Em 2009 esse número aumentou para 5.806. No período de 03/2010 a 11/2010 o Parque Viva a Ciência atendeu, através de agendamento e em pleno funcionamento, 11.810 alunos de escolas do ensino básico, fundamental e médio da rede pública e privada de Santa Catarina.

Desde sua inauguração, foram recebidas 7.114 pessoas, chamadas de público espontâneo. Este número contabiliza os visitantes recebidos durante a Semana de Ensino, Pesquisa e Extensão da UFSC de 2008, 2009 e 2010, bem como os visitantes recebidos durante todo o período de atendimento do Parque.

A tabela a seguir mostra o número de visitantes em 2010, discriminados entre o tipo de instituição e o ciclo em que se encontram os estudantes:

Tabela 1 - Visitantes do Parque Viva a Ciência em 2010.

\begin{tabular}{llll}
\hline \multicolumn{1}{c}{ Ciclo } & \multicolumn{1}{c}{ Público } & \multicolumn{1}{c}{ Particular } & Total \\
\hline Infantil & 525 & 76 & 302 \\
Fundamental 1 & 3.295 & 1.165 & 3.797 \\
Fundamental 2 & 3.725 & 1.142 & 4.211 \\
Ensino Médio & 1.345 & 537 & 1.486 \\
\hline Total & 8.890 & 2.920 & 11.810 \\
\hline
\end{tabular}

Fonte: Os autores.

Em valores absolutos, 75,3\% dos visitantes atendidos no Parque provêm das escolas públicas. Estes alunos representam 0,73\%, de um total de 1.215.350 matriculados na rede pública de Santa Catarina (INEP, 2010b). Os visitantes das escolas particulares, apesar de em menor número absoluto, representam 1,78\%, uma fração maior do universo de 164.450 matriculados (INEP, 2010b).

A tabela mostra que predominam visitantes do ciclo Fundamental 2, que correspondem a $35,6 \%$ do total do público atendido. Este ciclo é o que possui o maior número de matriculados, totalizando 450.188 estudantes das escolas públicas e privadas de Santa Catarina (INEP, 2010b). Os 4.211 visitantes correspondem a 0,94\% desses alunos, o maior índice de visitas entre os ciclos.

Em 2010 estiveram matriculados no ensino básico de Santa Catarina 1.379.800 alunos. Atuando próximo de sua capacidade máxima de atendimento, o Parque recebeu 
11.810 destes estudantes, que, por sua vez, representam apenas 0,86\% dos alunos do estado. O pleno funcionamento do Parque em 2010 revelou que há uma grande demanda reprimida por este tipo de serviço, uma vez que as vagas esgotam-se poucos dias após o início do agendamento para o semestre.

\section{CONSIDERAÇÕES FINAIS}

O Parque Viva a Ciência ao longo dos anos de 2009-2010 recebeu mais de 27.000 pessoas. Os estudantes da rede pública da grande Florianópolis que visitaram o espaço, durante todo o ano de 2010, representam apenas cerca de 1,5\% (aproximadamente 4.279 09/2010) dos matriculados da região.

Foi cedido à UFSC um terreno de $50.000 \mathrm{~m}^{2}$, localizado à beira-mar, próximo ao campus de Florianópolis, para a construção de um novo planetário, um centro de capacitação de professores e uma grande área de $29.000 \mathrm{~m}^{2}$ de lazer ao ar livre permeada de instalações para divulgação científica. Uma vez implementado o Parque Viva a Ciência na nova área do aterro da Baía Sul, o público atendido deverá quintuplicar logo nos primeiros meses após a inauguração de uma estrutura mínima, mas já muito maior do que a atualmente disponível.

Talvez seja impossível verificar qual a influência de uma visita a um Museu de Ciências na vida de uma pessoa (SMITH, 1990). No entanto, segundo Wagensberg (2005), um Museu de Ciências é um espaço dedicado a fornecer estímulos para o conhecimento científico, um local do qual os visitantes acabam saindo com mais perguntas do que quando entraram. Diferentemente, o Parque Viva a Ciência está se propondo a abrir novos horizontes pessoais e talvez profissionais para os estudantes da rede pública catarinense.

\section{REFERÊNCIAS}

ABCMC. Associação Brasileira de Centros e Museus de Ciências. Guia de Centros e Museus de Ciências do Brasil 2009. Disponível em:

$<$ http://www.casadaciencia.ufrj.br/Publicacoes/guia/files/ guiacentrosciencia2009.pdf $>$. Acesso em: 15 dez. 2010.

CHINELLI, M. V.; PEREIRA, G.R.; AGUIAR, L. E. V. Equipamentos interativos: uma contribuição dos centros e museus de ciências contemporâneos para a educação científica normal. Revista Brasileira de Ensino de Física, 2008, v. 30, n. 4 , p. 4505.1-4505.10.

FEZB. Fundação Ecológica e Zoobotânica de Brusque. 2010. Disponível em:

$<$ http://www.brusque.sc.gov.br/web/noticia.php?noticia=1344:Parque_Zoobotanico_de_Brus que_faz_balanco_e_comemora_resultados>. Acesso em: $13 \mathrm{dez} .2010$. 
IBGE. Instituto Brasileiro de Geografia e Estatística. Censo 2010a. Disponível em: $<$ http://www.censo2010.ibge.gov.br/primeiros_dados_divulgados/index.php?uf $=42>$. Acesso em: 30 nov. 2010.

Instituto Brasileiro de Geografia e Estatística. Censo 2010b. Disponível em: $<$ http://www.ibge.gov.br/cidadesat/link.php?uf=sc>. Acesso em: 30 nov. 2010>.

INEP. Instituto Nacional de Estudos e Pesquisas Educacionais Anísio Teixeira. Educacenso 2009a. Disponível em: <http://www.inep.gov.br/download/censo/2010/anexo_I.xls>. Acesso em: 15 dez. 2010.

Instituto Nacional de Estudos e Pesquisas Educacionais Anísio Teixeira. 2009b.

Disponível em:

$<$ http://www.inep.gov.br/basica/censo/Escolar/Matricula/censoescolar_2010.asp?metodo=1\& ano $=2010 \& U F=$ SANTA + CATARINA $\&$ MUNICIPIO $=\&$ Submit $=$ Consultar $>$. Acesso em: 15 dez. 2010.

MARANDINO, M. A pesquisa educacional e a produção de saberes nos museus de ciência. História, Ciências, Saúde - Manguinhos, v. 12, suplem., p. 161-81, 2005.

SMITH, J. K. Methods of Measuring Learning - In: What Research Says about Learning in Science Museuns - ASTC, 1990, p. 16-18.

VCU. Venha Conhecer a UFSC. 2010. Disponível em: <http://www.venhaconhecer.ufsc.br>. Acesso em: 15 dez. 2010.

WAGENSBERG, J. O museu "total", uma ferramenta para a mudança social. In: $4^{\circ}$ Congresso Mundial de Centros de Ciência. Rio de Janeiro, 2005. Disponível em: $<\mathrm{http}: / /$ www.fiocruz.br/museudavida_novo/4scwc/Texto\%20Provocativo\%20\%20Jorge\%20Wagensberg.pdf $>$. Acesso em: 12 ago. 2011. 